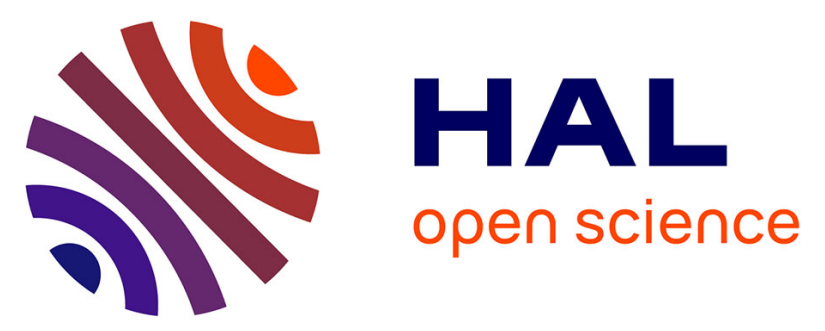

\title{
Development of a Line for Dissolved Inorganic Carbon Extraction at LMC14 Artemis Laboratory in Saclay, France
}

\author{
J.P. Dumoulin, I Caffy, C Comby-Zerbino, E Delqué-Količ, S Hain, M \\ Massault, C Moreau, A Quiles, V Setti, C Souprayen, et al.
}

\section{To cite this version:}

J.P. Dumoulin, I Caffy, C Comby-Zerbino, E Delqué-Količ, S Hain, et al.. Development of a Line for Dissolved Inorganic Carbon Extraction at LMC14 Artemis Laboratory in Saclay, France. Radiocarbon, 2013, 55 (2), pp.1043-1049. 10.1017/S0033822200058173 . hal-03207652

\section{HAL Id: hal-03207652 https://hal.science/hal-03207652}

Submitted on 18 Jun 2021

HAL is a multi-disciplinary open access archive for the deposit and dissemination of scientific research documents, whether they are published or not. The documents may come from teaching and research institutions in France or abroad, or from public or private research centers.
L'archive ouverte pluridisciplinaire HAL, est destinée au dépôt et à la diffusion de documents scientifiques de niveau recherche, publiés ou non, émanant des établissements d'enseignement et de recherche français ou étrangers, des laboratoires publics ou privés. 


\title{
DEVELOPMENT OF A LINE FOR DISSOLVED INORGANIC CARBON EXTRACTION AT LMC14 ARTEMIS LABORATORY IN SACLAY, FRANCE
}

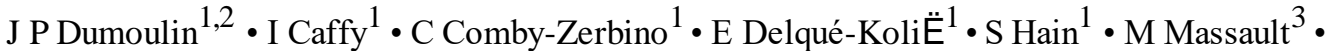 \\ $\mathrm{C}_{\text {Moreau }}{ }^{1} \cdot \mathrm{A}_{\text {Quiles }}{ }^{1} \cdot \mathrm{V} \mathrm{Setti}^{1} \cdot \mathrm{C}$ Souprayen $^{1} \cdot \mathrm{J}^{-\mathrm{F}_{\text {Tannau }}}{ }^{4} \cdot \mathrm{B}_{\text {Thellier }}{ }^{1} \cdot \mathrm{J}_{\text {Vincent }}{ }^{1}$
}

ABSTRACT. We present here the new line installed at the LMC14 laboratory (Saclay, France) for dissolved inorganic car-bon (DIC) extraction from marine and freshwater samples. The operating system and extraction process are described. The efficiency of the line design was checked, and the background $(0.42 \pm 0.11 \mathrm{pMC})$ and the reproducibility on artificial samples obtained by dissolution of IAEA-C1, IAEA-C2, and commercial bicarbonate in water were evaluated. An intercomparison with an independent lab (IDES) was also carried out on a natural sample. The line processes 3 samples a day under a helium flow and is able to run samples up to $40,000 \mathrm{ka}$.

\section{INTRODUCTION}

Radiocarbon measurement of dissolved inorganic carbon (DIC) has been shown to be a powerful tool for studying the carbon cycle, ocean dynamics, and freshwater residence time. It enables inor ganic matter and water masses to be tracked and the age of groundwater to be evaluated. Analyses of ${ }^{14} \mathrm{C}$ DIC are generally performed by accelerator mass spectrometry (AMS) using both static (i.e. Fontes 1971) and dynamic (under He flow) lines (e.g. Bard et al. 1989).

Since 2003, the Laboratoire de Mesure du ${ }^{14} \mathrm{C}$ (LMC14, Saclay, France) has operated as a support laboratory for the French scientific community, carrying out ${ }^{14} \mathrm{C}$ measurements from chemical prep-aration to AMS measurements, in fields such as quaternary geology, environmental sciences, and archaeology. While manual and automatic preparation lines have been developed for carbonate and organic samples (Tisnérat-Laborde et al. 2001; Hatté et al. 2003), a DIC extraction line was recently built. This new facility will be able to handle both seawater and freshwater samples and will be a useful tool for researchers working with the LMC14.

The aim of this paper is to present the LMC14C DIC extraction line, how it works, and its range of applications. First, the $\mathrm{CO}_{2}$ extraction process will be described. The architecture of the system is then tested by comparing external ${ }^{13} \mathrm{C}$ measurements on different samples to assess fractionation during $\mathrm{CO}_{2}$ production. Different ${ }^{14} \mathrm{C}$ datings of background samples obtained from IAEA-C1 mar-ble and a bicarbonate sample $\left(\mathrm{CHNaO}_{3} / \mathrm{Acros}\right)$ diluted with boiled deionized water are presented. The data are compared to classical carbonate extractions from powders of the same samples. Lastly, other tests on IAEA -C2 travertine diluted with boiled ultrapure water and real water samples from the groundwater of Square Lamartine in Paris are shown and compared with results obtained in another laboratory.

\footnotetext{
${ }^{1}$ Laboratoire de Mesure du Carbone 14 (LMC14), CEA Saclay, Bâtiment 450 porte 4E, 91191 Gif-sur-Yvette Cedex, France. ${ }^{2}$ Corresponding author. Email: Jean-Pascal.Dumoulin@ lsce.ipsl.fr.

${ }^{3}$ Laboratoire Interactions et Dynamique des Environnements de Surface IDES, CNRS-Université Paris-Sud 11, 91405 Orsay Cedex, France.

${ }^{4}$ Laboratoire des Sciences du Climat et de 1'Environnement (LSCE), Avenue de la Terrasse, 91198 Gif-sur-Yvette Cedex, France.
} 


\section{METHODS}

\section{System Description and Functionality}

We developed the DIC extraction system based on a manual procedure for operation at the Labora-toire des Sciences du Climat et de l'Environnement LSCE (Bard et al. 1989; Leboucher et al. 2004). The line and storage vials are made of glass (Figure 1). Vacuum is ensured by an oilfree primary pump coupled to a turbopump able to achieve a residual pressure $<10^{5} \mathrm{mbar}$. The line includes a water container, a stripping vessel, 2 water traps cooled to $80^{\circ} \mathrm{C}$ by a mixture of dry ice and alco-hol, 1 liquid nitrogen trap to trap evolved $\mathrm{CO}_{2}$, and a calibrated cold finger used to measure the amount of extracted $\mathrm{CO}_{2}$ (Figure 1). The line is fed by a helium gas flow ( $\mathrm{CO}$ and $\mathrm{CO}_{2}<0.1 \mathrm{ppm}$ ), which is monitored with a flowmeter (Figure 1).

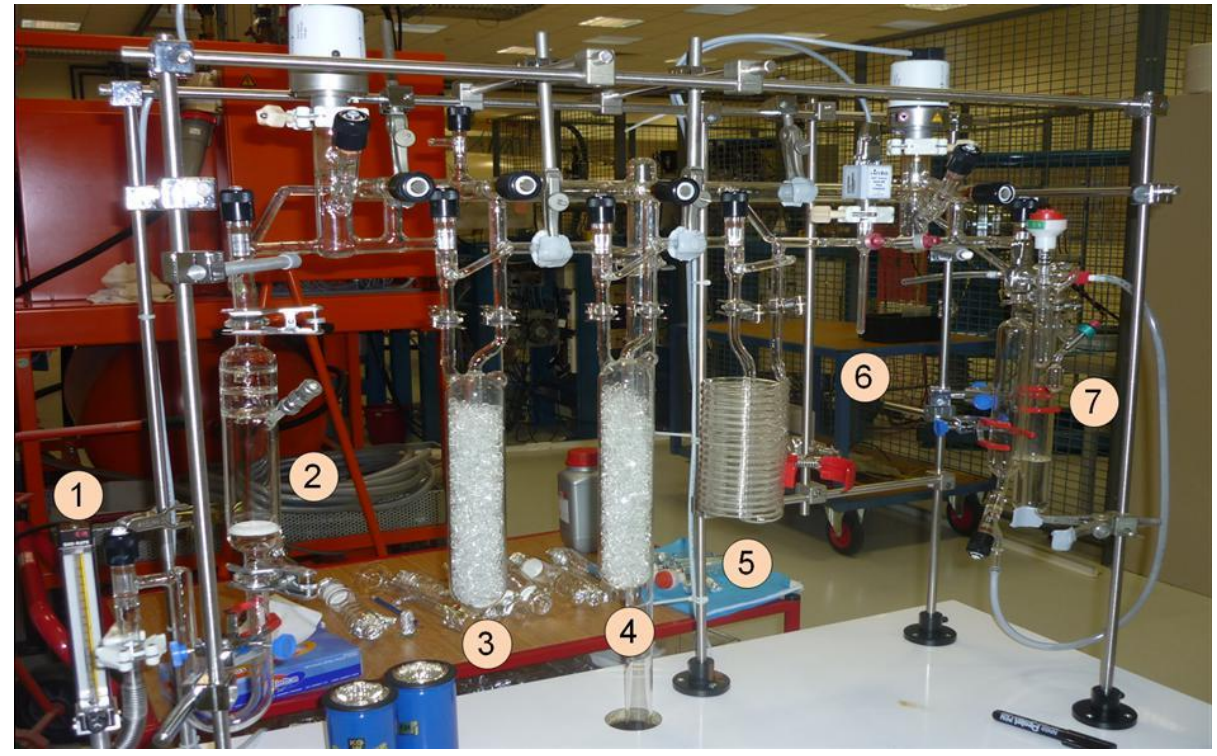

Figure 1 Photograph of the DIC extraction line. 1: the flowmeter; 2: stripping vessel; 3,4, 5: cold traps (respectively at 80, 80 , and $190^{\circ} \mathrm{C}$ ); 6: cold finger with a MKS gauge; 7:2 aliquots in 2 different vials. Vacuumis generated by a dry primary pump coupled to a turbopump. Residual pressure is measured by 2 full range Pfeiffer gauges.

\section{FUNCTIONALITY}

The system is first evacuated until a residual pressure $<10{ }^{5} \mathrm{mbar}$ is obtained, and the water traps are cooled to $80^{\circ} \mathrm{C}$ and the $\mathrm{CO}_{2}$ trap to $190^{\circ} \mathrm{C}$. A pure helium flow is then introduced to fill the sys-tem and regulated with a flowmeter until a pressure just above atmospheric pressure is reached. Between 70 and $100 \mathrm{~mL}$ of water, depending on the DIC content, is introduced into the stripping vessel pushed by pure argon gas $\left(\mathrm{CO}\right.$ and $\left.\mathrm{CO}_{2}<10 \mathrm{ppb}\right)$ out of the original water bottle. The $\mathrm{CO}_{2}$ is evolved with the introduction of $2 \mathrm{~mL}$ of $85 \%$ phosphoric acid and then dried on the 2 water traps at $80^{\circ} \mathrm{C}$ before being trapped at $190^{\circ} \mathrm{C}$.

After $1 \mathrm{hr}$, the amount of $\mathrm{CO}_{2}$ produced from the DIC is measured in a calibrated cold finger with a MKS gauge and separated into 2 aliquots: one for AMS and the other for ${ }^{13} \mathrm{C}$ measurement carried out by an isotope ratio mass spectrometer (Dual Inlet VG Optima through a manifold). The $\mathrm{CO}_{2}$ gas is then transferred to a graphitization line and reduced to graphite on iron with excess of hydrogen at $600{ }^{\circ} \mathrm{C}$ (Arnold et al. 1987, 1989). The iron and graphite powder is pressed into a 1-mm aluminum 
cathode for measurement on the Artemis accelerator (LMC14 UMS 2572, Saclay) (Cottereau et al. 2007). ${ }^{14} \mathrm{C}$ activity is normalized ${ }^{13} \mathrm{C}=25 \%$. Conventional ${ }^{14} \mathrm{C}$ age calculations are done using the Mook and van der Plicht method (1999). Errors take into account the statistics, results variability, and background correction.

Taking into account the time required to properly evacuate the line between 2 consecutive samples and the time to run a sample, 3 samples a day can be run on the line. To avoid any crosscontamina-tion, the $80{ }^{\circ} \mathrm{C}$ dry ice alcohol mixture is removed and the water traps are dried between 2 consec-utive samples.

\section{SAMPLES}

\section{Background Samples}

Due to the difficulty in finding water samples for background evaluation, we made artificial water samples by dissolving different kinds of ${ }^{14} \mathrm{C}$ reference powders such as IAEA-C1 marble, IAEA$\mathrm{C} 2$ travertine, or bicarbonate $\left(\mathrm{NaHCO}_{3} / \mathrm{Acros}\right)$ in boiled deionized water $(18 \mathrm{M})$. The deionized water is boiled to remove, as far as possible, the modern $\mathrm{CO}_{2}$ in equilibrium with the water, since the hotter the water, the lower the $\mathrm{CO}_{2}$ content.

To reproduce the same conditions as with regular water samples, we performed the dissolution in borosilicate bottles similar to those used for regular water sampling. As the borosilicate bottles con-tain nearly $280 \mathrm{~mL}$, around $40 \mathrm{mg}$ of each powder was diluted to obtain nearly $1 \mathrm{mg}$ of $\mathrm{CO}_{2}$ per $70 \mathrm{~mL}$ aliquot of water. The powder is first introduced in the bottle and then the water is added. The bottle is filled until $1 \mathrm{~cm}$ from the top to leave space for the greased (silicon) glass plug. Finally, the bottle is checked to dissolve the powder and the artificial sample is used no more than 15 min later, when it is a little cooler and less dangerous to handle the bottle. The rationale for preparing these artificial samples was to reproduce as closely as possible the operating conditions encountered with water to be dated, in particular when introducing the water into the line.

\section{Reproducibility and Intercomparison Samples}

To both test the reproducibility on regular samples and to allow comparison with another ${ }^{14} \mathrm{C}$ laboratory, we collected freshwater samples from a fountain of the artesian well of Passy in Paris. Sam-ples were collected in 280- $\mathrm{mL}$ glass bottles (Figure 2 and Appendix). As the water does not flow continuously but is stopped with a faucet, we let the water flow for $10 \mathrm{~min}$ before sampling and then closed the sample bottles quickly to avoid equilibration with modern $\mathrm{CO}_{2}$. The samples were not poisoned with $\mathrm{HgCl}_{2}$ but were stored at $4{ }^{\circ} \mathrm{C}$ overnight. $\mathrm{CO}_{2}$ extraction was done the following day.
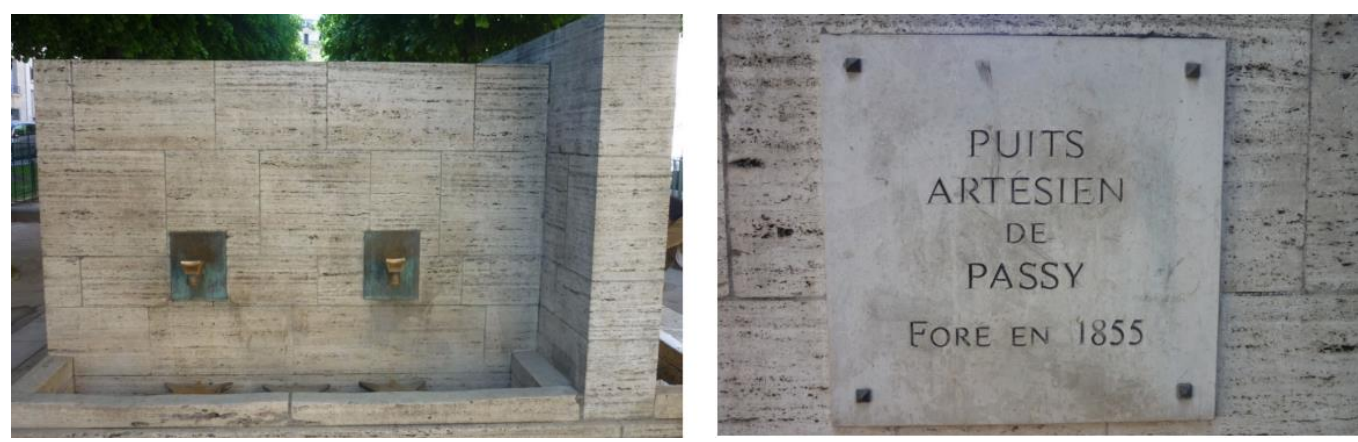

Figure 2 Square Lamartine fountain (the artesian well of Passy in Paris, France) 


\section{RESULTS AND DISCUSSION}

\section{Test of Line Geometry and Fractionation}

To check the adequacy of the line geometry and to ascertain whether the system was efficient in pro-viding reliable ${ }^{14} \mathrm{C}$ results, we first tried to produce $\mathrm{CO}_{2}$ from an IAEA-C1 marble powder without any added water or He flow. For this purpose, we adapted a carbonate reactor to evolve $\mathrm{CO}_{2}$ by acid attack. The value obtained on this acid-treated $\mathrm{C} 1$ (Table 1) was similar to that obtained on regular manual and automated lines dedicated to carbonate commonly used by LMC14 (Tisnérat-Laborde et al. 2001).

Table 1 IAEA-C1 marble powder activity. The $\mathrm{CO}_{2}$ is produced without any water or He flow.

\begin{tabular}{lllll}
\hline Sample code & Nature & $\mathrm{mg} \mathrm{C}$ & $\mathrm{pMC}$ & ${ }^{14} \mathrm{C}$ date BP \\
\hline SacA-26318 & $\mathrm{C} 1$ & 0.56 & $0.13 \pm 0.01$ & $53,510 \pm 550$ \\
\hline
\end{tabular}

To ensure that the system did not involve any fractionation during the $\mathrm{CO}_{2}$ production, we compared the ${ }^{13} \mathrm{C}$ obtained on $\mathrm{CO}_{2}$ evolved from DIC on the LMC14 DIC extraction line (SacA28478 and SacA-28480) to the ${ }^{13} \mathrm{C}$ of $\mathrm{CO}_{2}$ evolved from bicarbonate powder itself by acid attack (SacA-28392 and SacA-28316). The results (Table 2) indicate scattering between samples that underwent similar treatment, for both DIC extraction and acid attack. Nevertheless, there was no statistical dif-ference between the 2 approaches. The lowest scattering was recorded for artificial C2 samples (Table 3) and the value is statistically in agreement with the C2 consensus value. It can thus be con-cluded that the LMC14 line does not induce extra isotopic fractionation.

Table 2 Comparison between the ${ }^{13} \mathrm{C}$ of the bicarbonate powder and the ${ }^{13} \mathrm{C}$ of the bicarbonate with water.

\begin{tabular}{clll}
\hline Sample code & Nature & ${ }^{13} \mathrm{C} \%$ o & Average \\
\hline $\mathrm{SacA}-28392$ & Bicarbonate powder & $4.70 \pm 0.07$ & $4.51 \pm 0.27$ \\
$\mathrm{SacA}-29316$ & Bicarbonate powder & $4.32 \pm 0.06$ & \\
\hline $\mathrm{SacA}-28478$ & Bicarbonate $+\mathrm{H}_{2} \mathrm{O}$ & $4.95 \pm 0.06$ & $4.71 \pm 0.35$ \\
$\mathrm{SacA}-28480$ & Bicarbonate $+\mathrm{H}_{2} \mathrm{O}$ & $4.46 \pm 0.13$ & \\
\hline
\end{tabular}

Table 3 Comparison between the ${ }^{13} \mathrm{C}$ of $\mathrm{C} 2$ and water and the ${ }^{13} \mathrm{C}$ of the $\mathrm{C} 2$ consensus value.

\begin{tabular}{lllll}
\hline $\begin{array}{l}\text { Sample } \\
\text { code }\end{array}$ & Nature & ${ }^{13} \mathrm{C} \%$ Average & Consensus value \\
\hline SacA-28489 & $\mathrm{C} 2+\mathrm{H}_{2} \mathrm{O}$ & $8.65 \pm 0.03$ & $8.66 \pm 0.2$ & $8.25 \pm 0.31$ \\
$\mathrm{SacA}-28490$ & $\mathrm{C} 2+\mathrm{H}_{2} \mathrm{O}$ & $8.87 \pm 0.05$ & & \\
$\mathrm{SacA}-28491$ & $\mathrm{C} 2+\mathrm{H}_{2} \mathrm{O}$ & $8.47 \pm 0.11$ & & \\
\hline
\end{tabular}

\section{TEST ON BACKGROUND AND COMPARISON SAMPLES}

We analyzed different ${ }^{14} \mathrm{C}$ background samples made from IAEA-C1 marble, IAEA-C2 travertine, and a bicarbonate sample ( $\mathrm{NaHCO}_{3} /$ Acros) diluted with boiled ultrapure water. The data were com-pared to the IAEA reference values based on acid attack of carbonate for $\mathrm{C} 1$ and C2 or to classical acid attack on carbonate for the bicarbonate (Tisnérat-Laborde et al. 2001). Results are shown in Tables 4, 5, and 6, where errors are given at the 1 level. 
We conducted a measurement on boiled deionized water alone in order to see whether $\mathrm{CO}_{2}$ was pro-duced when phosphoric acid was introduced. This test did not reveal the presence of any $\mathrm{CO}_{2}$, at least not within our detection and collection limits. This cannot necessarily be taken to mean, how-ever, that we had succeeded in removing all the modern $\mathrm{CO}_{2}$ in equilibrium with the water.

Table 4 Comparison between $\mathrm{C} 1+\mathrm{H}_{2} \mathrm{O}$ activity and the consensus value for $\mathrm{C} 1$.

\begin{tabular}{llllll}
\hline Sample code & Nature & $\mathrm{mg} \mathrm{C}$ & pMC & Average & Consensus value \\
\hline $\mathrm{SacA}-28481$ & $\mathrm{C} 1+\mathrm{H}_{2} \mathrm{O}$ & 0.76 & $0.54 \pm 0.02$ & $0.42 \pm 0.11$ & $0.00 \pm 0.02$ \\
$\mathrm{SacA}-28482$ & $\mathrm{C} 1+\mathrm{H}_{2} \mathrm{O}$ & 1.15 & $0.39 \pm 0.02$ & & \\
$\mathrm{SacA}-28483$ & $\mathrm{C} 1+\mathrm{H}_{2} \mathrm{O}$ & 0.76 & $0.33 \pm 0.02$ & & \\
\hline
\end{tabular}

Table 5 Comparison between $\mathrm{C} 2+\mathrm{H}_{2} \mathrm{O}$ activity and the consensus value for $\mathrm{C} 2$.

\begin{tabular}{llllll}
\hline Sample code & Nature & mg C & pMC & Average & Consensus value \\
\hline $\mathrm{SacA}-28489$ & $\mathrm{C} 2+\mathrm{H}_{2} \mathrm{O}$ & 0.82 & $41.08 \pm 0.19$ & $41.76 \pm 0.59$ & $41.14 \pm 0.03$ \\
$\mathrm{SacA}-28490$ & $\mathrm{C} 2+\mathrm{H}_{2} \mathrm{O}$ & 0.94 & $42.07 \pm 0.19$ & & \\
$\mathrm{SacA}-28491$ & $\mathrm{C} 2+\mathrm{H}_{2} \mathrm{O}$ & 0.83 & $42.14 \pm 0.2$ & & \\
\hline
\end{tabular}

Table 6 Comparison between the bicarbonate powder activity and the bicarbonate $+\mathrm{H}_{2} \mathrm{O}$ activity.

\begin{tabular}{lllll}
\hline Sample code & Nature & $\mathrm{mg} \mathrm{C}$ & $\mathrm{pMC}$ & Average \\
\hline SacA-28392 & Bicarbonate powder & 1.45 & $0.48 \pm 0.02$ & $0.485 \pm 0.007$ \\
SacA-28393 & Bicarbonate powder & 1.34 & $0.49 \pm 0.02$ & \\
\hline $\mathrm{SacA}-28478$ & Bicarbonate $+\mathrm{H}_{2} \mathrm{O}$ & 1.25 & $0.85 \pm 0.03$ & $0.85 \pm 0.02$ \\
$\mathrm{SacA}-28479$ & Bicarbonate $+\mathrm{H}_{2} \mathrm{O}$ & 0.55 & $0.87 \pm 0.02$ & \\
$\mathrm{SacA}-28480$ & Bicarbonate $+\mathrm{H}_{2} \mathrm{O}$ & 0.85 & $0.83 \pm 0.03$ & \\
\hline
\end{tabular}

All the measured ${ }^{14} \mathrm{C}$ activities are higher than expected by $0.42 \mathrm{pMC}$ for $\mathrm{C} 1$ and $0.62 \mathrm{pMC}$ for $\mathrm{C} 2$. The contamination is of the order of $1 \%$ modern carbon or lower. Indeed, $1 \%$ of contamination by modern carbon would result in an increase of $1.07 \mathrm{pMC}$ on $\mathrm{C} 1$ and bicarbonate and of $0.66 \mathrm{pMC}$ on $\mathrm{C} 2$. These values, higher or similar to those obtained in this work, show that modern contamination remains acceptable (maximum $1 \%$ ). The introduction of modern $\mathrm{CO}_{2}$ can be explained by the trans-fer of the water from the sampling bottle to the "stripping vessel" (with argon) or because the line is flushed by helium. Both gases might carry some carbon. However, as both these gases were very pure, this is unlikely to be the main explanation.

The principal source of contamination was undoubtedly the fact that we prepared the water samples ourselves: even if deionized water is boiled, it may still contain trace amounts of dissolved modern $\mathrm{CO}_{2}$. It is very difficult to obtain water that is completely free of dissolved modern $\mathrm{CO}_{2}$. Our aim in preparing artificial water samples was to create operating conditions that were as similar as possible to those of a water sample introduced into the line. This enabled us to demonstrate that the line does not induce ${ }^{13} \mathrm{C}$ fractionation and that the water inlet system is efficient (no entry of air). Neverthe-less, this is not entirely sufficient for ${ }^{14} \mathrm{C}$ analysis, since small amounts of modern dissolved $\mathrm{CO}_{2}$ remain, distorting the measurements. The best way to assess the characteristics of the line would therefore be to use powders directly for the standard and background solutions, without adding any water. Indeed, since the $\mathrm{CO}_{2}$ production of the real water samples on the line will be conducted with-out the addition of boiled deionized water, it is not necessary to do so for the background and stan-dard samples. It is clear that the background and standard samples would be much better without the 
addition of deionized water and that one would obtain $<1 \%$ of contamination, with values likely closer to those of Table $1(0.13 \mathrm{pMC}$ for the $\mathrm{C} 1)$.

In the current conditions and with the tests previously carried out, the line background with $\mathrm{C} 1$ and boiled deionized water is taken as $0.42 \pm 0.11 \mathrm{pMC}$. This value allows measurement of samples of 0.64 pMC (mean +2 ), i.e. water samples up to 40,000 yr old. This value takes into account the con-tribution of the following steps: $\mathrm{CO}_{2}$ production; reduction to graphite; measurement with the accel-erator; and especially the contamination by modern $\mathrm{CO}_{2}$ induced by our artificial test samples.

\section{INTERCOMPARISON WITH ANOTHER LABORATORY}

To test the system with natural groundwater, samples were obtained from the artesian well of Passy in Paris. The objective was to compare our measurements with those of the IDES laboratory (Orsay, France), which has studied groundwater for many years. In contrast to our line, the IDES one is not flushed with helium. To ensure comparison of line quality only, $\mathrm{CO}_{2}$ evolved from both lines was reduced, pressed, and measured at $\mathrm{LMC} 14$ with the same procedure (see Table 7). The AMS back-ground measured on Ceylon background samples is estimated at 71,700 BP and is therefore negli-gible. For the $\mathrm{LMC1} 4$ series, we used the average of the $\mathrm{C} 1$ samples measured in the present study $(\mathrm{R} 14=0.0041)$ and for IDES we used their background value associated with this series $(\mathrm{R} 14=0.0029)$.

Table 7 Different ${ }^{14} \mathrm{C}$ measurements for Square Lamartine water samples (well of Passy in Paris) from 2 laboratories: LMC1 4 and IDES.

\begin{tabular}{lllll}
\hline Sample code & Nature & $\mathrm{mg} \mathrm{C}$ & $\mathrm{pMC}$ & Average \\
\hline SacA-28486 & LMC14 Square Lamartine & 1.47 & $3.54 \pm 0.14$ & $3.56 \pm 0.42$ \\
SacA-28487 & LMC14 Square Lamartine & 0.83 & $3.99 \pm 0.13$ & \\
SacA-28488 & LMC14 Square Lamartine & 1.46 & $3.15 \pm 0.13$ & \\
\hline SacA-28493 & IDES Square Lamartine & 0.5 & $2.98 \pm 0.11$ & $3.35 \pm 0.32$ \\
SacA-28494 & IDES Square Lamartine & 0.75 & $3.59 \pm 0.10$ & \\
SacA-28495 & IDES Square Lamartine & 0.75 & $3.42 \pm 0.10$ & \\
\hline
\end{tabular}

In both laboratories, we note a scattering of the results obtained from the same water sample collected in different bottles during the same sampling process. This variability is $\sim 10 \%$ of the nominal value. However, the mean values and scattering are similar and statistically in agreement between the 2 labs. Further intercomparison with this laboratory is planned on future water samples. The scattering is not yet well understood. Certain hypotheses can be suggested and should be further investigated: water turbulence within the fountain that induces more or less modern $\mathrm{CO}_{2}$ dissolu-tion, and the line itself through the helium or static trapping steps.

\section{CONCLUSION}

We have developed a new line devoted to water DIC extraction. ${ }^{13} \mathrm{C}$ results highlight that the line is well designed and does not induce any significant fractionation during $\mathrm{CO}_{2}$ production. Based on artificial water samples prepared from IAEA-C1 and commercial bicarbonate, we showed a contamination corresponding to less than $1 \%$ of modern carbon. The origin of the modern contamination might come from the line itself (with the helium flux or during the introduction of the water with argon), but the main reason appears to be the use of artificial samples (boiled water re-equilibrated with modern $\mathrm{CO}_{2}$ ). In this study, we wished to test the whole process using water samples, but the presence of modern dissolved $\mathrm{CO}_{2}$ proved to be a stumbling block. In future work, it would be pref- 
erable to measure the background and standard samples directly on powders, without adding boiled deionized water. This is warranted by the fact that deionized water is never added to the raw water samples to be measured.

The comparison of ${ }^{14} \mathrm{C}$ results obtained on the same batch of natural water samples between LMC14 and IDES shows similar values that are statistically in agreement, despite some data scattering. With our artificial background water samples, by combining background evaluation and heterogeneity, we consider that the line can process samples up to $0.64 \mathrm{pMC}$ ( $40 \mathrm{ka})$. While this is quite satisfac-tory, much lower values could no doubt be obtained if $\mathrm{C} 1$ powder samples were used directly. It would also be interesting to find very old water in order to obtain a background value directly on a water sample. For now, the system and the extraction process can be considered to be valid for use on real water samples and in different research areas.

\section{ACKNOWLEDGMENTS}

We wish to thank $\mathrm{C}$ Hatté for fruitful discussions and for the ${ }^{13} \mathrm{C}$ measurements on an isotopic ratio mass spectrometer. We thank $\mathrm{M}$ Fontugne and $\mathrm{N}$ Tisnérat- Laborde for advice on the process of the DIC extraction line. We would like to express our sincerest thanks to the 2 anonymous reviewers for their highly constructive comments and suggestions.

\section{REFERENCES}

Arnold M, Bard E, Maurice P, Duplessy J-C. 1987. ${ }^{14} \mathrm{C}$ dating with the Gif-sur-Yvette Tandetron accelerator: status report. Nuclear Instruments and Methods in Physics Research B 29(1-2):635-45.

Arnold M, Bard E, Maurice P, Valladas H, Duplessy JC. 1989. ${ }^{14} \mathrm{C}$ dating with the Gif-sur- Yvette Tandetron ac-celerator: status report and study of isotopic fraction-ation in the sputter ion source. Radiocarbon 31(3): 284-91.

Bard E, Arnold M, Toggweiler JR, Maurice P, Duplessy JC. 1989. Bomb ${ }^{14} \mathrm{C}$ in the Indian Ocean measured by accelerator mass spectrometry: oceanographic implications. Radiocarbon 31(3):510-22.

Cottereau E, Arnold M, Moreau C, Baqué D, Bavay D, Caffy I, Comby C, Dumoulin J-P, Hain S, Perron M, Salomon J, Setti V. 2007. Artemis, the new ${ }^{14} \mathrm{C}$ AMS at LMC14 in Saclay, France. Radiocarbon 49(2):291- 9.
Fontes J-C. 1971. Un ensemble destiné à la mesure de l'activité du radiocarbone naturel par scintillation liq-uide. Revue de Géographie Physique et de Géologie Dynamique 13(1):67-86.

Hatté C, Poupeau J-J, Tannau J-F, Paterne M. 2003. Development of an automated system for preparation of organic samples. Radiocarbon 45(3):421-30.

Leboucher V, Jean-Baptiste P, Fourré E, Arnold M, Fieux M. 2004. Oceanic radiocarbon and tritium on a transect between Australia and Bali (eastern Indian Ocean). Radiocarbon 46(2):567-81.

Tisnérat-Laborde N, Poupeau J-J, Tannau J-F, Paterne M. 2001. Development of a semi-automated system for routine preparation of carbonate samples. Radiocar-bon 43(2A):299-304.

Mook WG, van der Plicht J. 1999. Reporting ${ }^{14} \mathrm{C}$ activities and concentrations. Radiocarbon 41(3):227-39.

\section{APPENDIX: SOME HISTORICAL INFORMATION ABOUT LAMARTINE FOUNTAIN}

The drilling of the second artesian well in Paris in 1855 was undertaken by contractor Saxon Kind and initiated by engineer Jean-Charles Alphand. For this drilling, a well casing $1.10 \mathrm{~m}$ in diameter and $5 \mathrm{~mm}$ thick was chosen. All went well until the middle of drilling when several successive inci-dents occurred. The well casing was ripped and a thicker replacement casing with a smaller diameter of $0.70 \mathrm{~m}$ was used instead.

The Albian aquifer was finally reached at $586 \mathrm{~m}$ in 1861 . The flow rate was stabilized at $\sim 5000 \mathrm{~m}^{3}$ per day, and the water was used mainly to feed rivers and lakes of the newly developed Bois de Bou-logne. A fountain in Square Lamartine in the 16th arrondissement of Paris provides the public with water from the artesian well. It is used by many locals, who consider it an excellent water source. 